Notwithstanding what the doctor has said to the contrary, I should be sorry to leave the restoration of the bone in partial fracture to the curative action of the muscles, \&c. Ten months ago, having to treat a complete fracture of the forearm in a person about thirty-five years of age, who, being very anxious to go to business, in spite of my remonstrances to the contrary, at the end of six weeks after the fracture, would and did put off the splints. The arm at this time looked remarkably well, and the bones upon examination appeared to be firmly united, but judging from the short period of time that had elapsed, that a sufficient quantity of ossific matter had not been deposited, it was thought unsafe to remove them. The patient, however, took the responsibility upon himself, and merely kept the arm in a sling. In about a week afterwards, by leaning against the body, and by using the arm, the bones had become bent inwards and somewhat twisted, so that considerable deformity was produced, which remains to this day. I am quite aware that this is not a parallel case, but it serves clearly to show that the bones of the forearm, whether partially or completely fractured, after being replaced, must not be left, without efficient continuous support, to the efforts of nature.

With all due respect to the doctor, I therefore bey to say in conclusion, that the truth of his opinion is not substantiated, and the goodness of his practice, so far as regards mechanical treatment in these cases, is, "non pioven." I am, Sir, your obedient servant,

Bristol, Nov. 12, 1841.

$$
\text { James Prowse. }
$$

\section{PARTURITION WITHOUT CONSCIOUSNESS THEREOF.}

\section{To the Editor of THE LANCET.}

Sir,-Some time since I was sent for to attend a young married woman in her first confinement. The message was sent immediately on the waters being suddenly and unexpectedly discharged. I had to ride a distance of three miles, but found she had had no pains, and she assured me the discharge of waters was not attrncled with any uneasiness, not even sufficient to have awiked her, had she happened to be asleep at the time.

On examination $I$ found the os nteri dilated, and the head presenting. The child was slowly and unintermittingly, but forcibly, expelled. She betraycd no symptoms of uneasiness whatever, and though I watched her countenance, she did not exhibit the least consciousness of the child's expulsion, but expressed her surprise on seeing it. The child was strong and lively, and, with the mother, did well. The mother was about two-and-twenty, short, plechoric, and healthy. She was strictly respectable, and had been married full ten months; indeed, she could have no motive whatever for disguising her feelings.

I conceive the above case is interesting in a medico-legal point of view. Dr. Montgomery doubts the possibility of such an occurrence, "excepting under peculiar circumstances, certainly not in a first delivcry." -(Dr. M.'s "Exposition of the Signs and Symptoms of Pregnancy.") In Beck's "Medical Jurisprudence" it is said that " the possibility of a woman being delivered without being conscious of it is disbelieved, excepting some extraordinary and striking cause intervene." But if such a circumstance can happen with a first child, it must have its full weight in cases of infanticide. I am, Sir, your obedient servant,

Kegworth, Leicestershire, T. E. Rawson, Surgeon.

Nov. 19, 1841.

\section{PRESSURE DURING PARTURITION.}

\section{To the Editor of The Lancer.}

SIR,-As anything which tends to shorten the pain and suspense of a patient in childbed, and lessen the anxiety of the modical attendant, as well as sire his valuable time, cannot be too well known, perhaps you will oblige me by inserting the following in the pages of your widely-distributed Journal.

I have been in the habit, for some years past, after having ascertained that labour has commenced, of placing loosely around the body of the patient, exterior to her clothes, a thin shawl. The umbilical cord being tied and divided, I then tighten the shawl as much as the patient is capable of bearing, an assistant at the same time keeping it as wide and low down as possible. It has the effect of not only occasioning immediate separation of the placenta, which is found low down in the vagina (except where morbid adhesion exists), but it also acts most beneficially by preventing dilatation and hæmorrhage, to which, in some cases, there is such a predisposition. The patient generally expresses the comfont she derives from the pressure to which she is subjected.

I do not take credit to myself for anything original in the above, but knorving that it is not generally adopted, I am desirous of giving it publicity. I am, Sir, your obedicnt servant,

Wolverhampton, Nov. 19, 1841.

\author{
James Gatis, Surgeon.
}

\section{PAIN IN THE TIBIA REMOVED BY INCISION.}

\section{To the Elitor of The Lancet.}

SIR,-The interesting case of severe pain in the tibia relieved by ixcision, narrated by Mr. Freeman, in your last Number, induces 